\title{
Developing Audiences Through Outreach and Education in the Major Performing Arts Institutions of Hong Kong: Towards a Conceptual Framework
}

\author{
Fanny Ming Yan Chung ${ }^{1}$ (1)
}

Received: 17 November 2020 / Accepted: 28 May 2021 / Published online: 4 June 2021

(c) Fudan University 2021

\begin{abstract}
The public's participation rate in performing arts in Hong Kong has historically been low, and the Arts Participation and Consumption Survey in 2018 indicated that the primary reason was 'a lack of interest' and that education in the arts could increase public involvement. The survey data clearly indicate the significance of education as a driver to develop future audiences. There are nine major performing arts organisations funded by the Hong Kong government, and they share the responsibility of shaping the performing arts landscape. This study explored the role of outreach and education within these major performing arts organisations and how they impact audience development. In addition to document analysis and fieldwork, the researcher interviewed five cultural leaders from the nine performing arts organisations. The findings of this study indicate that while the organisations' outreach and education engagement help to achieve various important educational goals, direct impact on ticket sales is not easily quantifiable and may occur in the long run. This study concludes by offering a proposed conceptual framework for outreach and education when they are positioned in non-profit performing arts organisations. The four layers in the proposed conceptual framework involve cognitive, affective, ethical, and behavioural dimensions. It contributes to reframing the conceptualisation of audience development for the performing arts and sheds new light on the future of outreach and education in arts organisations and policymaking in arts and culture, with far-reaching implications for other non-profit cultural organisations in Hong Kong and globally.
\end{abstract}

Keywords Outreach · Arts education · Performing arts - Audience development · Cultural management

Fanny Ming Yan Chung

fannychung@arts.cuhk.edu.hk

1 Present Address: Cultural Management Programme, Faculty of Arts, The Chinese University of Hong Kong, Rm 206, Leung Kau Kui Building, Shatin, New Territories, Hong Kong, China 


\section{Introduction}

Under Hong Kong's current arts funding mechanisms, nine major performing arts organisations (MPAOs), known as the 'Big Nine', are directly funded by the government of the Hong Kong Special Administrative Region (HKSAR). These are the Hong Kong Philharmonic Orchestra, Hong Kong Chinese Orchestra, Hong Kong Sinfonietta, Hong Kong Repertory Theatre, Chung Ying Theatre Company, Zuni Icosahedron, Hong Kong Dance Company, Hong Kong Ballet, and City Contemporary Dance Company. These nine MPAOs cover three main forms of performing arts: music, dance, and drama. Most of these organisations were established in the late 1970s or early 1980s, with some originally founded by the government and some established by private arts groups or independent artists. In financial year 2020/21, these nine MPAOs secured over USD 52 million (Home Affairs Bureau 2020) to develop and shape the performing arts landscape in Hong Kong. Works produced by these nine MPAOs range from classical music to experiential theatrical works (Hong Kong Arts Development Council 2018). In addition to delighting audiences in Hong Kong and globally with their performing arts programmes, all nine actively support outreach and education programmes (OEPs) which play a significant role in developing audiences, sourcing additional income, and promoting the arts to the public. They actively organise a range of educational activities to support professional development for artists and create opportunities for the public to engage in the arts. In particular, because the public's participation rate in the performing arts has historically been low (Hong Kong Arts Development Council 2018), there is a pressing need for the performing arts sector to develop high-quality outreach programmes tailored to the artistic and educational needs of the public.

Audience development is a key objective of the arts sector in Hong Kong. The Arts Participation and Consumption Survey (Hong Kong Arts Development Council 2018) indicated that a 'lack of interest' (74.9\%) was the primary reason for the public's non-participation in arts activities, followed by 'more convenient and cheaper to watch on other media' (14.4\%), 'lack of a companion' (13.2\%), and 'money issues' (12.7\%). Moreover, it is of crucial importance to note that a considerable number of arts participants (43\%) stated that exposure to the arts through education had a significant influence on their involvement in the arts. These data demonstrate the significance of outreach and education as drivers that can increase public interest in the arts and develop future audiences. Nonetheless, despite the substantial resources allocated to and growing importance of outreach and education in the MPAOs, no studies have thus far investigated the outcomes and impacts of these efforts. As the first study focusing on Hong Kong's MPAOs' education and outreach, this study aims to: (1) examine the roles of OEPs in performing arts organisations from the perspectives of cultural leaders, (2) document the outcomes and impacts of OEPs on the audience development of the MPAOs, (3) identify the conditions that challenge the development of OEPs in the MPAOs, and (4) propose a conceptual framework for the role of outreach and education when they are positioned in non-profit performing arts organisations. 
Data were gathered through documentary analysis, fieldwork, and in-depth interviews with five Hong Kong cultural leaders at director, head, and manager levels in the nine MPAOs.

This study sheds new light on the contexts and impacts of outreach and education by non-profit performing arts organisations. It also contributes to the understanding of audience building in performing arts and has significant implications for cultural organisations' planning and arts and culture policymaking. In particular, its findings contribute to reframing the conception of outreach and education in non-profit performing arts organisations, with wider implications for other art forms (e.g. visual arts and media arts) and global practices in arts and culture. The findings can inform the design, planning, and implementation of OEPs in non-profit performing arts organisations, helping to ensure optimal impacts on the long-term sustainable development of such organisations.

The research questions are as follows:

$R Q 1$ What are the roles and underlying ideologies of the OEPs in the MPAOs?

$R Q 2$ Do the OEPs affect audience-building and increase audience size?

$R Q 3$ What challenges are faced by the MPAOs in implementing the OEPs?

\section{The Development of Arts and Culture in Hong Kong}

Hong Kong is a metropolitan city of over seven million people where Western and Chinese cultures meet; the HKSAR government has devoted substantial resources to the development of arts and culture. As shown in Fig. 1, in 2020/21, it allocated over \$700 million to arts and culture, excluding capital works (Home Affairs Bureau 2020). These resources primarily covered the provision of performance venues, funding support for arts groups, arts education, advocacy, and relevant administrative costs. Of the $\$ 700$ million, more than $\$ 52$ million (8\%) was designated for the MPAOs and \$23.5 million (3\%) was given to the Arts Development Council to support small to medium-sized performing and visual arts organisations.

In addition to ticketed performances, arts education, audience-building activities, and audience outreach and education are among the key performance indicators (KPIs) for the MPAOs (Home Office Bureau 2019). Tremendous effort and resources have been allocated to both outreach and education in many MPAOs. Through documentary analysis (e.g. annual reports of the MPAOs and other government documents), website research, and the researcher's fieldwork, the OEPs of the MPAOs can be categorised into three types: (1) in-house training, which encompasses masterclasses, workshops, class series, and rehearsals; (2) schoolbased training, including in-school concerts, interactive performances, school tours, teacher training, workshops, and exhibitions; and (3) community outreach, including outdoor concerts, lunchtime concert series, dance parties, caring community visits, and competitions. Table 1 summarises the categories and major types of OEPs offered by the MPAOs. 


\section{PROVISION FOR THE ARTS AND CULTURE (2020-21 ESTIMATES)}

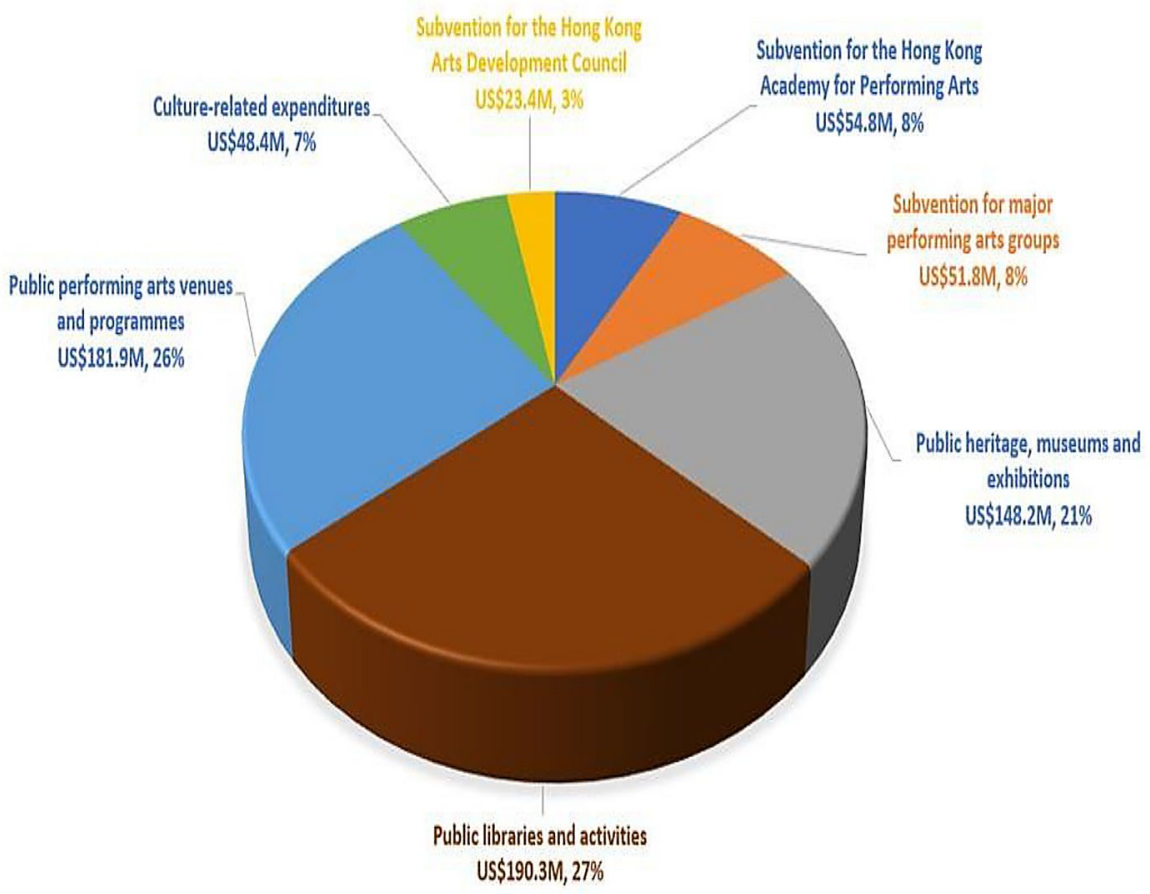

Fig. 1 HKSAR government funding for arts and culture. Source: Home Affairs Bureau (2020)

\section{Outreach and Audience Development in the Performing Arts}

Scholars have attempted to define 'outreach' and 'audience development' in the context of arts and culture. Yoshimoto (2001) defines 'outreach' and 'outreach activities' as the efforts of cultural facilities and arts organisations to provide residents and communities with more opportunities for contact with the arts. Maitland (2000) defines 'audience development' as a planned process that involves building a relationship between individuals and the arts. Single (1991) defines 'audience development' as building larger audiences through a combination of promotion, publicity, marketing, communications, education, and outreach. Finally, the Australian Council for the Arts (2015) defines audience development as a strategic, dynamic, and interactive process of making the arts accessible.

Outreach and education are pivotal for audience development and the survival of performing arts organisations. Given shrinking audiences and increasing competition from a range of leisure activities, arts establishments globally have increasingly focused on audience development (Scollen 2009). Davis (1983) suggests that audience education can help encourage people to attend plays. Single (1991) maintains that audience development is not only about quantity but also 


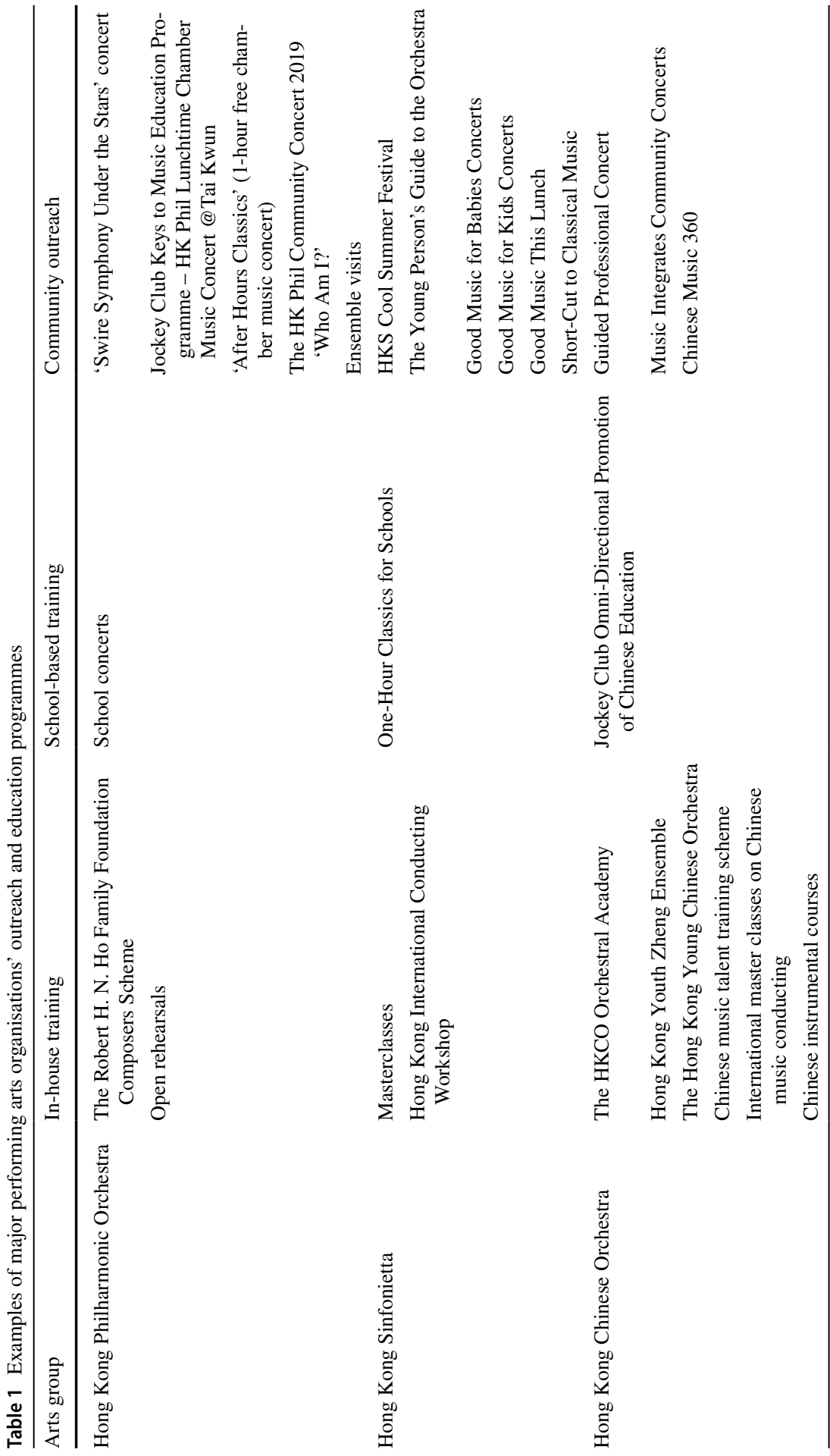




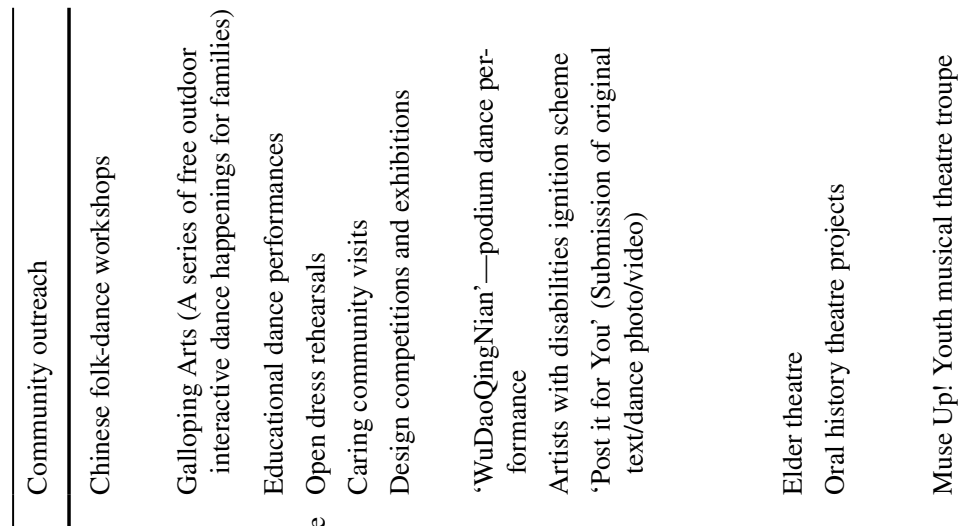

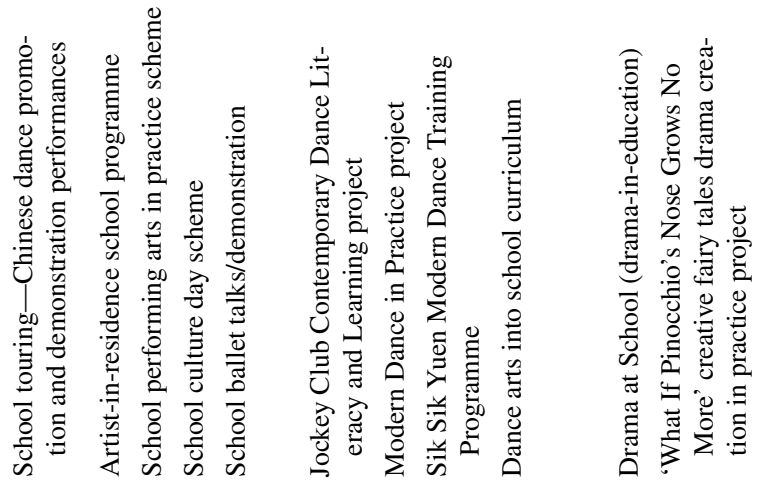

눙

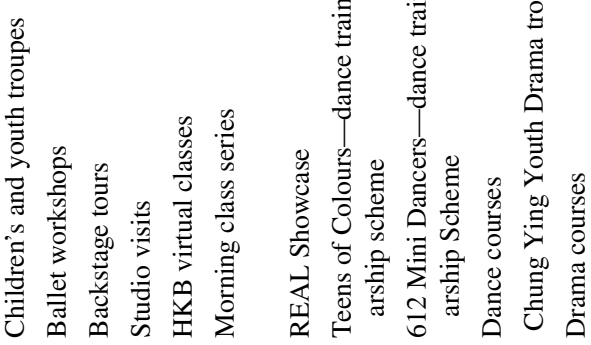

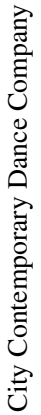

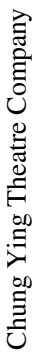




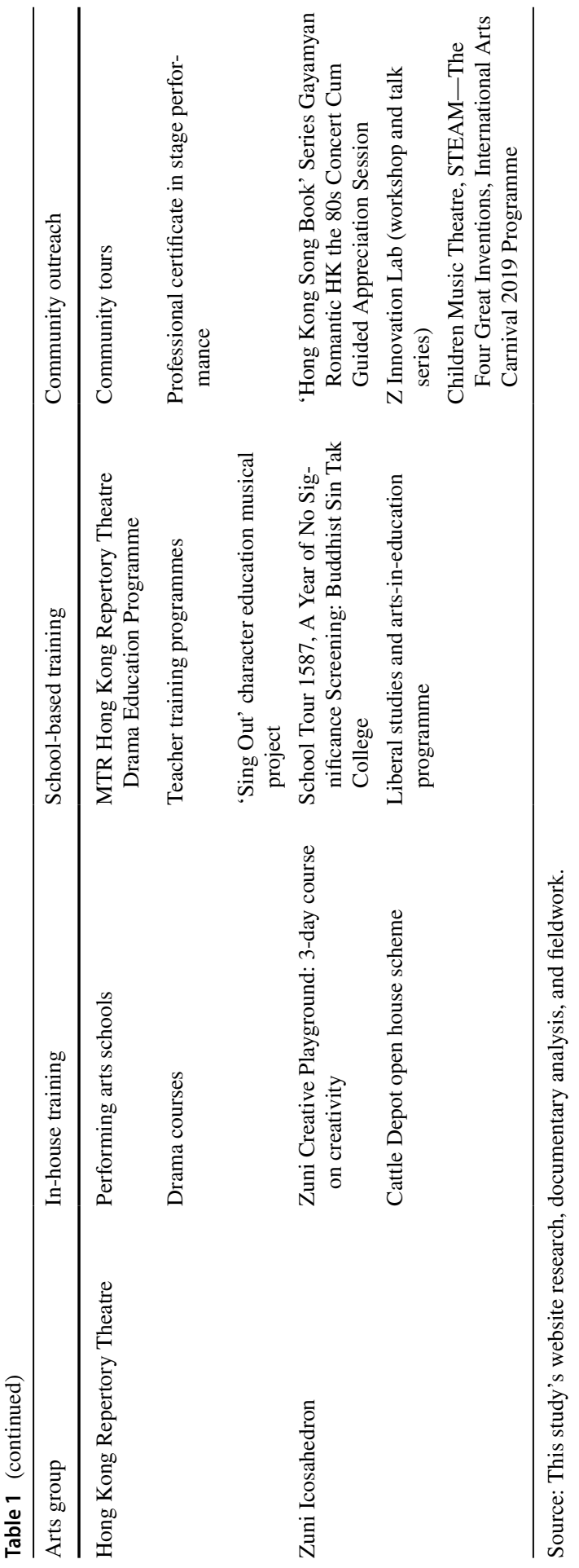


about quality. Sorjonen and Uusitalo (2005) note that audience education aims to change the behavioural patterns of audiences, urging them to accept and like the offered performances.

There are four types of audience development in performing arts according to Kawashima's (2000) conceptual framework: (1) cultural inclusion, (2) extended marketing, (3) taste cultivation, and (4) audience education. According to Kawashima $(2000,8)$, cultural inclusion 'targets the group of people who for apparently social reasons are the least likely to attend the arts'. This notion is largely substantiated by the prevalence of high-income earners, the middle-aged, and well-educated people who attend the theatre (Scollen 2008; Throsby and Withers 1979; Gourdon 1992; Bennett et al. 1999; Woolcott Research 2000). Kawashima (2000) explains that extended marketing focuses on people who have high attendance potential but are not yet theatregoers. Swollen (2008) indicates that this group are likely to be highly educated with high incomes (see also Bennett et al. 1999; McCarthy et al. 2001). Kawashima $(2000,9)$ defined taste cultivation as a strategy that 'seeks to introduce different art genres and forms to attenders of specific art forms to nurture theatre-goers' tastes and broaden their experiences in the arts'. Kawashima $(2000,9)$ describes audience education as an approach that 'tries to enhance [new or potential audiences'] understanding and enjoyment of the arts which existing attenders currently consume, enhancing the audience's artistic literacy to facilitate enjoyment'.

To increase audience participation, performing arts organisations globally have been progressively developing programmes to encourage audience participation and broaden their audience bases. For example, the Guthrie Theatre in Minneapolis was purposively built in an undeveloped area of the city in conjunction with high-end condos and parking garages, surrounded by built-up urban areas with the intention to shorten the distance between the audience and its ability to access the theatre (Markusen and Brown 2014). This location was also thought to offer increased engagement opportunities with the performing arts and thereby create audience appeal for the performances. 'Test Drive the Arts', a 1-year audience development programme in Australia, provided participants with two complimentary tickets to attend a live performance (Scollen 2009). Participants were also invited to attend a second performance at a discounted rate and a third performance with other incentives such as a complimentary drink. Another well-known audience development programme in Australia, 'Talking Theatre', provided participants with complimentary tickets to three live performances. Participants were then invited to attend future performances with occasional incentives. Both 'Test Drive the Arts' and 'Talking Theatre' gained positive results- an average of $30 \%$ of participants purchased tickets as a result of the programmes.

\section{Methodology}

Adopting a qualitative approach, data were gathered via semi-structured interviews with five cultural leaders in Hong Kong. Interviews can provide in-depth information about participants' experiences and viewpoints on a particular topic (Turner 2010). The participant selection criteria were arts administrators in senior MPAO 
Table 2 Interview example questions

How do you perceive the role of OEPs in non-profit performing arts institutions?

What are the major contributions of your OEPs?

Can you highlight your OEPs creative and innovative ideas?

What role do OEPs play in your organisation?

Do you think OEPs contribute to your organisation's box office performance?

As one of the major nine performing arts organisations in Hong Kong, what are the conditions that support and challenge your OEPs?

positions with substantial experience in the performing arts industry (music, dance, and theatre); these criteria were set to obtain in-depth, comprehensive, insightful, and true information about the ideologies and practices of the organisations' outreach and education engagement. With this purposive sampling method (Bryman 2016), the interviewees were carefully selected to ensure that they all had a thorough understanding of their organisation's practices, aspirations, and ideologies in audience development, and all played a pivotal role in audience development in their respective organisations. All the interviewees held senior positions in the MPAOs: director, head, or senior manager. The interviewees were Mr. Raymond Wong (Managing Director, City Contemporary Dance Company), Ms. Meggy Cheng (Director of Marketing, Hong Kong Philharmonic Orchestra), Ms. Patricia Sun (Head of Programme, Education and Touring, Hong Kong Chinese Orchestra), Ms. Kitty Kong (Education and Outreach Manager, Chung Ying Theatre Company), and Mr. Luka Wong (Manager, PR and Partnership Development, Zuni Icosahedron). The researcher invited the interviewees in writing, clearly explaining the study purpose and interview procedures; all agreed to participate and waive their anonymity.

The interviews were conducted in 2019 and 2020 and ranged from 30 minutes to 2 hours in duration. Originally, all interviews were meant to be in person, either in the interviewee's office or in other public areas; however, owing to the COVID-19 outbreak in Hong Kong, the government strongly encouraged social distancing, and the last two interviews were conducted by phone. Interviews were recorded, transcribed verbatim, and interpreted through content and thematic analyses. The process of thematic analysis seeks to identify, analyse, and interpret patterns of meaning in interviews (Gavin 2008). Table 2 presents example interview questions.

\section{Results}

\subsection{RQ1: What Are the Roles and Underlying Ideologies of the OEPs in the MPAOs?}

As revealed by this study, the roles and underlying ideologies of OEPs in the MPAOs are organised into three areas. 


\subsubsection{Cultivation of Aesthetic Appreciation and Enhancement of Perception of the Arts}

Interviewees noted the importance of cultivating public interest in the performing arts through their organisations' OEPs. Mr. Raymond Wong, Managing Director of the City Contemporary Dance Company, noted:

Arts groups often tend to focus on aesthetic education but focus less on cultivating interest. Although knowledge-based education is easier for the public (for example, schools) to accept, it is possible that gaining knowledge has no relation to cultivating interest. As such, I would focus on both 'knowledge' as well as 'interest'.... Just asking students to come to watch the CCDC's [City Contemporary Dance Company's] performance is not effective enough for audience-building, as students may still lack interest in watching without cultivating.

Ms. Meggy Cheng, Director of Marketing of the Hong Kong Philharmonic Orchestra, emphasised that OEPs are a foundation and steppingstone for the public to cultivate their interest in classical music. She noted:

We hope to make classical music more approachable through outreach programmes and to let the public know that they can enjoy at their ease and share with their friends. Our annual 'Symphony Under the Stars' is an excellent example: we take away all the boundaries of watching a concert and create an environment in an outdoor area where kids can run freely, the audience can eat and drink during the concert.... Many people are interested in classical music but might not be comfortable or used to going to the concert hall. Our outreach programmes allow them to give it a try and cultivate their interest.

Ms. Patricia Sun, Head of Programme, Education and Touring of the Hong Kong Chinese Orchestra coined the term 'sowing' to describe how outreach and education in performing arts organisations can cultivate interest. She stated:

Outreach and education play vital roles in providing opportunities for students to be exposed to the arts, although they may not develop a passion for the arts immediately through a single experience in arts participation. However, this 'sowing' effort will have a long-term impact. For example, if they are exposed to music again as they grow up, naturally, the music will become more familiar and approachable. As such, they will be more likely to develop their interest in music and subsequently become concertgoers.

Interviewees also noted the importance of developing the public's conception of the arts. Mr. Luka Wong, Manager (PR and Partnership Development) of Zuni Icosahedron said, "What is art?" is the main concept we would like to bring out in outreach and education. We hope that our work can enhance the aesthetic and knowledge development of participants. We tailor our workshops for different types of participants'. 
The interviewees in this study also shared their approaches and strategies to educating younger generations about the arts by extending the arts experience into schools. For example, Mr. Raymond Wong shared:

I value the concept of 'literacy'...We are hoping that the performances can really touch the students and make them perceive contemporary dance as something interesting and imaginative. When we run school tours, we often introduce contemporary dance through various approaches, including the use of plots and dialogues...We also presented videos about the personal stories and experiences of the dancers. It has been a success so far.

Ms. Meggy Cheng said, 'We are hoping to fill the gap in current school music education; for example, we have been holding master classes in schools and inviting our musicians to guide school orchestras'.

Further, Mr. Raymond Wong stressed the importance of teacher education in developing students' conceptions of and interest in the arts.

We have held workshops for the teachers as well so that they can bring contemporary dance into physical education classes in schools. According to the Education Bureau's Curriculum Guide, there is a component called 'creative dance' under the curriculum of physical education, but it seems that not many teachers are keen to teach it, as they do not know how to. Therefore, we hope to fill this gap.

\subsubsection{Enhancing Participants' Holistic Development}

Interviewees stated that OEPs can enhance participants' holistic development in many ways that transcend the intrinsic value of art itself. For example, Mr. Raymond Wong said:

Contemporary dance itself is more than art...for example, performers often use more than one language within the same performance, so this can be an excellent opportunity to enhance participants' linguistic competency.... We also hope to develop participants' concentration through all these arts experiences.

He further added that developing a strong and resilient mentality is among the important goals of outreach programmes:

Knowledge-based education is not our sole purpose. For example, when they participate in rehearsals or courses, we see their passion, openness, and perseverance as much more important than their skills in dance itself...we often see them develop professional attitudes [after the training], not just in terms of competence in dance, but also in terms of their mentality. Therefore, we are willing to assign them important roles in our performances even when they are relatively fresh in terms of technique. Although at the start, we may be concerned about their capability to bear such heavy and important responsibilities on the stage, we often end up happy with their performance. 
In this regard, Mr. Raymond Wong also noted the importance of the roles of educators in facilitating participants' holistic development.

Teachers teach students not only techniques, but also attitudes...in particular, morality is important in arts education; therefore, I believe that teachers need to show good attitudes to make positive impacts on the students... and building good values through education is crucial.

The Chung Ying Theatre Company's programme SMILE ${ }^{\mathrm{TM}}$ was specifically designed for developing young children's holistic development through drama. Ms. Kitty Kong, Education and Outreach Manager of the Chung Ying Theatre Company, explained the meaning of SMILETM:S for self-care, $\mathrm{M}$ for motor skills, I for intelligence, L for language, and E for emotion. She pointed out that according to their experience, role-play in drama enhances children's development in a range of aspects.

We adopted 'Drama in Education' and use stories and role-playing. For instance, children role-played in the drama 'Little Red Riding Hood' and everyone was trying to think of solutions and strategies to save Little Red. Throughout the process, children develop problem-solving skills and construct their own knowledge. Importantly, they also need to demonstrate their creativity and imagination when playing the roles in 'Little Red Riding Hood'... We found that children became braver after participating in the role-play activities and their critical thinking was enhanced.

\subsubsection{Developing Cultural Citizenship and Social Well-Being in Communities}

The cultural leaders shared their institutions' aspirations to enhance social wellbeing through participation in the arts, particularly among young people and working-class people. Mr. Raymond Wong stated:

Contemporary dance can go beyond the arts itself. Our theme often relates to societal and cultural issues... Our whole concept of outreach in the community is far beyond the purpose of audience development. Significantly, we do not want to neglect lower-class people.

Ms. Kitty Kong shared an example that demonstrates Chung Ying Theatre Company's tireless efforts to address social problems in Tin Shui Wai through the arts. Tin Shui Wai is an area in Hong Kong that has become widely known as the "city of sadness' because many of its inhabitants are new immigrants from mainland China living with hardship and unemployment and are unaccustomed to urban life. The Chung Ying Theatre Company developed the community art project 'Muse Up!' in 2008 for the community and established a youth troupe to create a musical training platform. Owing to the programme's success, in 2014, it was extended to Tung Chung, another area with a considerable number of new immigrants from mainland China who are financially disadvantaged. Ms. Kong said: 
There has been a lack of recreational facilities in Tin Shui Wai and consequently many youngsters wander the streets and the public estates, playing football after school. We think it is our responsibility to do something for this community through the arts, particularly for the underprivileged.

In addition to attending training sessions in musicals, participants are also required to contribute to the community through the arts and prove themselves as responsible citizens in the community. For example, they make frequent home visits to the elderly and demonstrate the outcomes of their musical training through their performances. Ms. Kong added:

Through the culture of our project, we hope that the youngsters become sensitive to the needs of the community. Some participants observed that some elderly people sat in McDonald's because they did not want to bother their families; some also noticed that some elderly people's family had migrated overseas, and they went to McDonald's at night to use the Wi-Fi. The participants subsequently integrated these elements within the community into their performances.

Ms. Kong also further shared that the topic for their recent programme is environmental protection in which participants engage in social services and distribute surplus food to the community. A drama that integrated their experiences was presented on a community tour of Tin Shui Wai, and a larger-scale drama performance will be held in the Jockey Club Auditorium.

\subsection{RQ2: Do the OEPs Affect Audience-Building and Increase Audience Size?}

Participants noted that their OEPs might have some immediate positive impacts on audience-building. Nevertheless, many stated that ticket-selling is not the ultimate goal of engaging in outreach and education. Ms. Patricia Sun noted that OEPs could help increase audience size, but more so over the long term than the short term:

Yes, outreach and education may help us build more potential audiences. For example, parents may buy their children concert tickets, if they tell their parents about their interest in Chinese music after attending our outreach programmes. However, overall, the impacts on the box office are likely to be in the long term, unless we really do something purposefully to push ticket sales. However, this is not our ultimate goal. As a representative Chinese orchestra in Hong Kong, our goal is to promote the genre of Chinese music.

Ms. Kitty Kong noted that the Chung Ying Theatre Company's matinees can successfully encourage university students and other young people to attend theatre performances, thereby increasing audience size. She added that the elderly and people who suffer from mental illness, who cannot afford the tickets otherwise, now have

\footnotetext{
1 An auditorium at the Hong Kong Polytechnic University that accommodates up to 1,084 people.
} 
opportunities to enjoy performances. She said, 'There are actually some impacts on the box office, but this absolutely is not our major target'.

Mr. Raymond Wong noted the ways in which the City Contemporary Dance Company's outreach engagement in schools has impacted audience development. The company has conducted OEPs (e.g. tours of dance centres, talks, and performances) for university students. They found that these programmes not only introduce the aesthetic beauty of contemporary dance to participating students, but surprisingly, students also took the initiative to recommend contemporary dance performances to their friends and peers who had not had any exposure to it. Mr. Raymond Wong noted:

If participating students take the initiative to invite their friends to the performances, this could be something powerful [for audience-building]. I think our approach has been successful. After all, the programming and themes are still the key factor to building our audience.

Importantly, all interviewees suggested that it is difficult to quantify and measure the effectiveness of OEPs in terms of audience-building, although they all recognised the value of these programmes in promoting their organisations and performing arts in the community. Mr. Raymond Wong said, 'It is difficult to measure the results of audience-building. It might require a longer time to see the result'.

Ms. Meggy Cheng explained:

Outreach and audience-building are a high priority in our organisation. It is difficult to quantify their impacts on the box office. We can keep track of the number of tickets purchased by our members, but it is difficult to measure how many tickets each member has purchased after they joined as a member, especially because the URBRIX system cannot provide these statistical data for us.

Ms. Patricia Sun expressed similar views:

Other than performing the main function of ticket selling, the current ticket selling system cannot provide any information for analysing who bought the tickets....We have tried to collect such information through the use of questionnaires, but with limited effectiveness as many audiences are not very responsive to questionnaires.

Mr. Luka Wong said that outreach and education can have an impact on audience development, though the impacts are difficult to define. He said:

In the short term, yes [to help build the audience] because outreach can function as a promotion that allows more people to learn about our work. Nevertheless, it is difficult to define long-term impacts, as they are difficult to quantify.

\subsection{RQ3: What Challenges are Faced by the MPAOs in Implementing Their OEPs?}

Some of the cultural leaders identified a major challenge as the need to position themselves appropriately as MPAOs directly funded by the government. Mr. Raymond Wong noted: 
The major challenge is to determine how to position ourselves in dance education, especially when there are already so many dance classes in the community. We are funded by the government, so we need to have a uniqueness in our market...we are hoping to discover something that others have not worked on.

Ms. Meggy Cheng also expressed that one of the challenges is to fully understand the organisation's unique position and, subsequently, actualise its missions:

We need to understand our position, that is, [one] of high artistic quality. Nevertheless, it is important to note that this does not mean we need to compromise our approachability. We need to let the public understand that orchestral music could be something approachable, that is why we held our Star Wars' concerts.... How to find a balance between upholding artistic excellence and approachability to the public is a major challenge.

Ms. Kitty Kong indicated that parents' expectations could be a challenge for arts organisations, particularly in conducting OEPs for young children. For example, the Chung Ying Theatre Company has organised drama-related OEPs for young children by adopting a creative and play-based approach.

Parents often have high expectations of our theatre company because we are a famous brand and are capable of providing large-scale performance opportunities for the children. We can basically meet parents' expectations. However, we have to keep reminding parents that they should not focus too much on their children's roles in the play.

As discussed above, some MPAOs have strived to use the arts as a vehicle for responding to community needs (i.e. as a fulfilment of social responsibilities). However, Ms. Kitty Kong noted that sometimes the public and government may have different views:

The public may have a misconception, 'Why do the arts groups engage in societal activities?' They think arts groups should focus on their performances. Some people in society still believe 'Art for art's sake' and that arts organisations should not put so many resources into community services. I think it is about the balance between the art itself and serving society.

Some arts administrators admitted that despite being directly funded by the HKSAR government, resource limitations remain a major concern, as Ms. Kitty Kong explained:

To fully actualise our work, we need substantial resources. We now have 15 full-time staff members and some part-time staff members, but the government's resources can only cater to several staff members. As such, we need to strive to obtain other funding sources.... It is important that we maintain a certain level of human resources to support the operation...some people think that we should just focus on arts development...people have different views. 
Ms. Patricia Sun noted that as a representative Chinese orchestra in Hong Kong, they have the social responsibility to promote the genre. However, misconceptions about the genre have posed challenges for them. She stated:

Many people in Hong Kong still have misconceptions about Chinese music, probably because of their educational backgrounds and greater exposure to Western music. Many people even still have the misconception that Chinese music is only for funeral or wedding ceremonies. As such, we need to engage in more 'sowing' work.

Mr Luka Wong noted that the traditional culture of some schools may hinder the creativity of performing arts groups and pose a great challenge.

We are quite different from the other eight MPAOs in that they focus more on their own genre, adopting a relatively more straightforward approach. We are more experiential, which involves different genres. For example, we invited Chinese opera artists to introduce Kunqu (a Chinese opera genre) to students. In fact, diversity in the outreach programmes is one of our key features and advantages. However, our diversity may not be accepted by all schools. Some schools prefer outreach programmes to be more traditional, and they may not accept our creativity, which is our major challenge.

\section{Discussion and Implications}

\subsection{Audience Development Components and Strategies in the OEPs of the MPAOs}

As revealed by this study, the MPAOs have adopted a wide range of audience development strategies through outreach and education to build audiences. In particular, some have made substantial efforts to dispel the stereotype that arts participation is only for the elite of society by organising cultural activities tailored for 'the group of people who for apparently social reasons are the least likely to attend the arts' (Kawashima 2000, 8). For instance, the Chung Ying Theatre Company's Community Art Project 'Muse Up!' is an excellent example of an arts organisation targeting disadvantaged youth in Tin Shui Wai and Tung Chung. Further, according to Kawashima (2000), extended marketing is also a vital type of audience development, and it refers to efforts made to entice people who have high attendance potential, but who are not yet customers (i.e. well-educated and high-income earners). Ms. Meggy Cheng, Director of Marketing of the Hong Kong Philharmonic Orchestra, has identified that people who take early retirement are highly likely to be concertgoers and orchestra customers:

Outreach programmes could be a good starting point for those who have retired early. In particular, music can enhance social well-being. Early retired people can afford to explore the world of music in terms of both money and time. They are even willing to pick up a new musical instrument and start from scratch. As such, we really need to take care of them. 
It is worth noting that some MPAOs have tried to expand their audience base by cultivating interest among those unaccustomed to traditional and formal theatrical settings. The Hong Kong Philharmonic Orchestra's 'Symphony Under the Stars' is an excellent example. Ms. Meggy Cheng shared her intentions and strategies in targeting people who were not regular concertgoers and lack knowledge of classical music. She said:

Our movie concert series is suitable for young working adults, and it can lead them to enjoy orchestral music through soundtracks from movies. We need to know what programmes we have on hand, how to target different audiences, and how to build their interest in the long term, not just as a one-off.

One important objective of OEPs is to enhance the artistic literacy of audiences to ultimately increase their enjoyment of the arts. Although all interviewees noted the difficulty in quantifying the empirical impacts of audience education, they agreed that audience education plays a significant role in nurturing audiences' artistic interest and literacy. Many of the MPAOs have committed to the development of OEPs by including outreach and education in their mission statements. For example, the City Contemporary Dance Company's mission statement says, 'As an agency for dance education, the CCDC organises the most comprehensive education and outreach programmes, with an emphasis on long-term projects in Hong Kong and in mainland China'. Further, the Chung Ying Theatre Company emphasises the important role of education, 'To enliven the cultural life of the community through outstanding plays and various education programmes'.

\subsection{Limitations in the Current Implementation of Outreach and Education}

The Arts Participation and Consumption Survey (Hong Kong Arts Development Council 2018) revealed that audience members for dance, music, and theatre in Hong Kong showed high overlap from 30.9 to $48.7 \%$. Despite the equal distribution of music, dance, and drama within the nine MPAOs, there has been little collaboration, and the opportunities for extending audiences' interest in the performing arts may have been hindered. In fact, the combined artistic merits and audience bases of these performing arts organisations have great potential to contribute to taste cultivation by broadening audiences' scopes of interest in performing arts. Fisher and Preece's (2002) study revealed that performing arts events are complements rather than substitutes; the more often an audience member attends performances of a specific art form, the more likely they are to commit to another. This helps dispel the notion of competition among performing arts organisations and thus encourages them to collaborate more closely to optimise audience building and to address their diverse needs and interests. For example, cross-over programming (i.e. a combination of different art forms in a single performance or throughout the season) is a potential way to satisfy an audience's diverse needs and broaden its base. Furthermore, as suggested by Ms. Meggy Cheng, the 'cultural passport' concept could be integrated into the Hong Kong performing arts context; with a single purchase, the passport allows and encourages a person to sample a variety of art forms. Such 
initiatives may be a way to nurture and broaden a person's artistic taste, knowledge, and interests.

\subsection{Proposed Conceptual Framework: Four Layers of the Role of OEPs in Non-Profit Performing Arts Organisations}

Based on the findings of this study and other literature on arts education and audience building (e.g. Chung 2021a; Kawashima 2000), the researcher proposes a conceptual framework for outlining and analysing the four layers of the role of outreach and education in performing arts organisations. To date, despite the growing importance of arts education components in performing arts organisations, there is no conceptual framework for this aspect of performing arts organisations. The framework could have significant implications for the future sustainable development of outreach and education in non-profit performing arts organisations and can serve as an important reference for further validation of this line of research. Specifically, this study has clearly demonstrated that the MPAOs in Hong Kong have devoted substantial efforts to outreach and education engagement with the aim of achieving a range of educational goals that the formal education system may have overlooked or failed to address. The four layers in the proposed conceptual framework involve cognitive, affective, ethical, and behavioural dimensions (Figure 2). Successful application of the framework, in addition to audience building, can augment the formal education system in several ways. The four proposed layers are explained below.

\subsubsection{Layer 1: Cultivation of Aesthetic Appreciation and Perception of the Arts}

According to Hachiya (2001), arts education enhances feelings of enjoyment, increases interest, develops knowledge, and enhances understanding of the arts. As shown in the present study, these educational activities contribute tremendously to the MPAOs' aspirations for nurturing public interest and enhancing arts literacy. Examples include in-house educational activities (e.g. professional training classes, classes for young children, and site visits), in-school educational activities (e.g. rehearsals, talks, masterclasses, workshops, and performances), community outreach (e.g. 'Muse Up!' by the Chung Ying Theatre Company), educational performances of various scales (including black box theatre and traditional theatre with significant capacity), and different formats (including outdoor performances such as 'Symphony under the Stars' by the Hong Kong Philharmonic Orchestra).

\subsubsection{Layer 2: Enhancement of Participants' Holistic Development}

Existing literature has indicated that high-quality and well-tailored arts education can improve people's ethical awareness, mental health, physical conditions, and knowledge and generic skills (e.g. language, social and communication, cognitive and physical development) (Barrett 2003; Campbell and Scott-Kassner 2009; Chung 2019; Gardner 1983; Piaget 1962; Suthers 2001). As revealed in the present study, the MPAOs regard outreach and education as a significant means to promote 
Behavioural dimension

Layer 4: Increased participation in the arts and audience-building

\section{Ethical dimension}

Layer 3: Development of cultural citizenship, responsible cultural community and social well-being

Layer 2: Enhancement of participants' holistic development

\section{Cognitive and affective dimensions}

Layer 1: Cultivation of aesthetic appreciation and perception of the arts

Fig. 2 Proposed conceptual framework: four layers of outreach and education in non-profit performing arts organisations

participants' all-round development. In addition, as reported above, the arts administrators shared examples of how participation in the arts contributes to participants' holistic development in such areas as linguistics, concentration, problem-solving, social-emotional well-being, passion, perseverance, creativity, and critical thinking.

\subsubsection{Layer 3: Development of Cultural Citizenship, Responsible Cultural Community, and Social Well-being}

Hachiya (2001) suggests that well-designed arts education can help to develop a sense of responsibility in the community, a greater understanding of self and society, improve human quality, enhance cultural and national identity, and promote higher ethics and morals. Chung's (2021b) study also noted that education plays a vital role in the development of cultural identity. As shown by this study, OEPs have significant potential to enhance social well-being, especially among lower-class and underprivileged people in the community, through the provision of various arts 
experiences. Indeed, the themes of many arts programmes are socially related (e.g. the community art project 'Muse Up!' by the Chung Ying Theatre Company). During these turbulent and challenging times both in Hong Kong and globally, enhancing cultural and community citizenship, in addition to social well-being, are integral to the long-term sustainable development of society.

\subsubsection{Layer 4: Increased Participation in the Arts and Audience-Building}

In practical terms, the participants in this study admitted that it is difficult to quantify the monetary impacts of outreach and education by measures such as box office sales. In fact, many of the participants have suggested that OEPs' impacts on audience size may only be measurable in the long term, rather than immediately. Nevertheless, this study has confirmed that to a large extent, the tireless efforts of outreach and education by performing arts organisations lead to audiences' increased interest, enthusiasm, and perseverance in the arts. These efforts may ultimately help performing arts organisations to develop wider, stronger, and more loyal audience bases.

\section{Conclusions}

The findings of this study suggest that non-profit performing arts organisations' OEP outcomes include (1) cultivating aesthetic appreciation and enhancing perceptions of the arts, (2) enhancing participants' holistic development, (3) developing cultural citizenship and social well-being, and (4) increasing participation in the arts and audience-building. These outcomes can serve in many ways to augment formal education. Although all interviewees endorsed the significant value of OEPs in performing arts organisations, the true impact on audience-building remains difficult to measure and quantify. A conceptual framework of the role of outreach and education in non-profit performing arts organisations has been proposed based on the findings of this study. This framework can help to inform future developments and programming in the outreach and education sector in non-profit performing arts organisations. Additionally, it will provide a frame of reference for positioning outreach and education within non-profit performing arts organisations and for policymaking in arts and culture, with wider implications for other non-profit cultural organisations (e.g. visual arts and new media arts) in Hong Kong and globally.

All research has its limitations, and my recommendations for future research stem from the limitations of this study. First, it was small in scale and only involved nonprofit performing arts organisations. In addition, collecting the perspectives of other stakeholders (e.g. teachers, school leaders, participants, and parents) of performing arts organisations was beyond the scope of this study. Nevertheless, it can be viewed as an important reference for future policymaking and development of outreach and education programmes. Future studies could include a wider population, with samples from other stakeholders in non-profit performing arts organisations in Hong Kong. A longitudinal study could also be designed to investigate the various long-term impacts of OEPs on young people. Importantly, the proposed four-layer 
conceptual model of the role of outreach and education in non-profit performing arts organisations can support and enable further validation of this line of research.

Above all, the cultural leaders participating in this study emphasised that ticketselling is not the ultimate and sole purpose of their OEPs. In this light, it is important to note that the focus of education in non-profit performing arts organisations should not be merely on the number of additional tickets sold; rather, cultivation of the public's interest and passion in the arts are the ultimate keys to audience building and the sustainable development of performing arts organisations, and this is a notably long-term process. With such an awareness of the unique features of outreach and education, performing arts organisations should view their dedicated efforts and resources in outreach and education engagement with a long-term vision.

Acknowledgments The author would like to sincerely thank Mr. Raymond Wong (Managing Director, City Contemporary Dance Company), Ms. Meggy Cheng (Director of Marketing, Hong Kong Philharmonic Orchestra), Ms. Patricia Sun (Head of Programme, Education and Touring, Hong Kong Chinese Orchestra), Ms. Kitty Kong (Education and Outreach Manager, Chung Ying Theatre Company), and Mr. Luka Wong (Manager, PR and Partnership Development, Zuni Icosahedron) for their kind support of this research.

Funding This study was funded by the Research Direct Grant from the Faculty of Arts, The Chinese University of Hong Kong (Project Reference Number: 4051124, CUHK).

\section{Declarations}

Conflict of interest The author certifies that no potential conflict of interests arose from this study.

\section{References}

Australia Council for the Arts. 2015. Arts nation: An overview of Australian arts. Sydney: Creative Commons.

Barrett, Margaret S. 2003. Belonging, being and becoming musical: An introduction to children's musical worlds. In Children, meaning-making and the arts, ed. Susan Wright, 57-84. Frenchs Forest, NSW: Pearson Higher Education.

Bennett, Tony, Michael Emmison, and John Frow. 1999. Accounting for tastes: Australian everyday cultures. Cambridge: Cambridge University Press.

Bourdieu, Pierre. 1986. Distinction: A social critique of the judgement of taste, trans. Richard Nice. London: Routledge.

Bryman, Alan. 2016. Social research methods, 5th ed. Oxford: Oxford University Press.

Campbell, Patricia Shehan, and Carol Scott-Kassner. 2009. Music in childhood: From preschool through the elementary grades, 3rd ed. New York: Schirmer Books.

Chung, Fanny. 2019. Interdisciplinary play-based approach in early childhood music education. In European perspectives on music education, ed. Monika Oebelsberger, Andreas Bernhofer, and Gerhard Sammer, 113-122. Vienna: Helbling.

Chung, Fanny. 2021b. Translating culture-bound elements: A case study of traditional Chinese theatre in the socio-cultural context of Hong Kong. Fudan Journal of Humanities and Social Sciences. https:// doi.org/10.1007/s40647-021-00322-w.

Chung, Fanny. 2021a. The impact of music pedagogy education on early childhood teachers' self-efficacy in teaching music: The study of a music teacher education program in Hong Kong. Asia-Pacific Journal of Research in Early Childhood Education 15: 63-86. https://doi.org/10.17206/apjrece. 2021.15.2.63

Davis, Ken. 1983. Background and foreground: Audience education from theory to practice. Paper presented at the Annual Meeting of the American Theatre Association, Minneapolis, pp 7-10. 
Fisher, Timothy, and Stephen B. Preece. 2002. Evaluating performing arts audience overlap. International Journal of Arts Management 4: 20-32.

Gardner, Howard E. 1983. Frames of mind: The theory of multiple intelligences. New York: Basic Books.

Gavin, Helen. 2008. Understanding research methods and statistics in psychology. London: SAGE.

Gourdon, Anne-Marie. 1992. The spectator's reception of theatrical performances. In Performance theory reception and audience research: Advances in reception and audience research, ed. Henri Schoenmakers, 115-120. Amsterdam: ICRAR/TTW publish.

Hachiya, Masayuki. 2001. Towards a theory of arts education. Master's dissertation, University of Toronto Canada.

Home Affairs Bureau. 2019. Contestable funding pilot scheme for the major performing arts groups. https://www.hab.gov.hk/en/policy_responsibilities/arts_culture_recreation_and_sport/funding_ pilot_scheme.htm. Accessed 12 November 2020.

Home Affairs Bureau. 2020. Government funding support to culture and the artshttps://www.hab.gov. hk/en/policy_responsibilities/arts_culture_recreation_and_s\%20port/arts.htm\#: :text=In\%202020\% 2D $21 \% 2$ C\%20the\%20Government, well $\% 20$ a $\% 20$ s $\% 20$ relevant $\% 20$ administrative $\% 20$ costs. Accessed 1 January 2020.

Hong Kong Arts Development Council. 2018. Arts participation and consumption survey (final) report. http://www.hkadc.org.hk/media/files/research_and_report/Arts\%20Participation\%20and\%20Con sumption $\% 20$ Survey $\% 20 \%$ E2\%80\%93\%20Final\%20Report/Arts\%20Participation\%20and\%20Con sumption\%20Survey\%20-\%20Final\%20Report.pdf. Accessed 1 January 2020.

Kawashima, Nobuko. 2000. Beyond the division of attenders vs. non-attenders: A study into audience development in policy and practice. Warwick: Centre for Cultural Policy Studies, University of Warwick. http://wrap.warwick.ac.uk/35926/

Leisure and Cultural Services Department. 2018. Statistics report. http://www.lcsd.gov.hk/en/aboutlcsd/ $\mathrm{ppr} /$ statistics/cultural.html\#Programmes.

Maitland, Heather. 2000. A guide to audience development. England: Arts Council of England.

Markusen, Ann, and Alan Brown. 2014. From audience to participants: New thinking for the performing arts. Análise Social 49: 866-883.

McCarthy, Kevin F., Arthur Brooks, Julia Lowell, and Laura Zakaras. 2001. The performing arts in a new era. Washington, DC: Rand Corporation.

Piaget, Jean. 1962. Play, dreams, and imitation in childhood. New York: Norton Library.

Sayre, Shay, and Cynthia M. King. 2003. Entertainment and society: Audiences, trends, and impacts. Thousand Oaks, CA: Sage.

Scollen, Rebecca. 2008. Regional voices talk theatre: Audience development for the performing arts. International Journal of Nonprofit and Voluntary Sector Marketing 13: 45-56.

Scollen, Rebecca. 2009. Talking theatre is more than a test drive: Two audience development methodologies under review. International Journal of Arts Management 12: 4-13.

Single, Nancy Ann. 1991. An arts outreach/audience development program for schools of music in higher education. Doctoral dissertation, Ohio State University.

Sorjonen, Hilppa and Liisa Uusitalo. 2005. Does market orientation influence the performance of art organizations? In Proceedings of AIMAC 8th International Conference on Arts \& Cultural Management, HEC Montréal, Canada (vol. 3). Montréal: AIMAC. http://neumann.hec.ca/aimac2005/PDF_ Text/SorjonenH_UusitaloL.pdf. Accessed 25 May 2021.

Suthers, Louie. 2001. Toddler diary: A study of development and learning through music in the second year of life. Early Child Development and Care 171: 21-32.

Throsby, Charles David and Withers, Glen A. 1979. The economics of the performing arts. Melbourne: Edward Arnold (Australia).

Turner, Daniel W. 2010. Qualitative interview design: A practical guide for novice investigators. Qualitative

Woolcott Research. 2000. Australians and the arts. Sydney: Australia Council.

Yoshimoto, Mitsuhiro. 2001. Outreach programmes bring the arts to children and local residents: The possibility for social service through the arts. http://www.unesco.org/new/fileadmin/MULTI MEDIA/HQ/CLT/CLT/pdf/Arts_Edu_RegSess_Symp_Asia_Yoshimoto.pdfpdf. Accessed 12 November 2020 